\title{
Determination of Salbutamol Sulfate in pharmaceutical formulation with differential pulse voltammetry using poly(Benzofuran-2-Boronic acid) modified platinum electrode
}

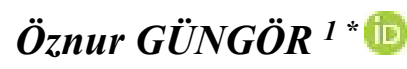 \\ ${ }^{1}$ Department of Chemistry, Faculty of Arts and Sciences, İönü University, 44280, Malatya / TURKEY
}

\begin{abstract}
In this study, determination of salbutamol sulfate (SBS) was carried out using poly(benzofuran-2-boronic acid)/platinum electrode (BF2BA/PtE). Polymerization of BF2BA was conducted in acetonitrile $(\mathrm{AcN})$ containing $0.1 \mathrm{M}$ sodium perchlorate $\left(\mathrm{NaClO}_{4}\right)$ on bare PtE by cyclic voltammetry (CV) method. The electrochemical properties of the prepared polymer electrode were investigated by $\mathrm{CV}$ and electrochemical impedance spectroscopy (EIS) techniques in ferricyanide/ $\mathrm{KNO}_{3}$ solution. Then, prepared poly(BF2BA/PtE) was used for detection of the SBS. Monomer type, concentration, the number of cycles and scan rate were worked using differential pulse voltammetry (DPV) in citrate-phosphate buffer containing $1.15 \mathrm{mM}$ SBS. The effects of parameters such as electrolyte type, pH effect on SBS DPV responses were studied. The SBS responses of the modified electrodes were also investigated by square wave voltammetry (SWV). The oxidative current peak stem from SBS concentration showed at $0.65 \mathrm{~V}$ potential and a linear calibration curve was obtained in the range from 50 to $2000 \mu \mathrm{M}$ SBS concentration. Limit of dedection (LOD), and limit of quantitation (LOQ), was calculated as $49.14 \mu \mathrm{M}$ and $163.80 \mu \mathrm{M}$, respectively. The recovery efficiency for synthetic urine samples was obtained from 91.47 to $110.43 \%$ by using BF2BA/PtE.
\end{abstract}

\author{
Article info \\ History: \\ Received: 24.04 .2021 \\ Accepted: 27.07.2021 \\ Keywords: \\ Benzofuran-2-boronic \\ acid, \\ Salbutamol sulfate, \\ Square wave \\ voltammetry, \\ Platinum electrode, \\ Sensor.
}

\section{Introduction}

Salbutamol (SBS) is a selective beta-2 adrenergic agonist and its IUPAC name is 2-(tert-butylamino)-1(4-hydroxy-3-hydroxymethyl) phenylethanol. The structure of SBS is shown in scheme 1. This agonist is used in the treatment of the distinctive feature of chronic obstructive pulmonary disease (COPD) and bronchial asthma [1].<smiles>CC(C)(C)NCC(O)c1ccc(O)c(CO)c1</smiles><smiles>O=S(=O)(O)O</smiles>

Scheme 1. Structural formula of salbutamol sulfate (SBS)

SBS, marketed as Ventolin, is usually considered the drug of choice as relief medication for symptoms of bronchospasm. It is an agonist of $\beta 2$ receptors which are present in the bronchioles of lungs of the human body. Athletes using $\beta 2$-agonists, usually inhale them prophylaxis prior to competition or training [2]. Especially during an asthma attack, since its effect starts quickly preferable. Apart from its metabolic side effects, many side effects can be seen in skeletal muscles, central nervous system and cardiovascular system [3]. For these potential side effects, detection of the SBS in body fluids and urine is very important. Spectrophotometric techniques [4-8], gas chromatography-mass spectrometry $[9,10]$, high performance liquid chromatography $[11,12]$, liquid chromatography-mass spectrometry [13-15], capillary electrophoresis [16-20] and chemiluminescence $[21,22]$ are used for the determination of salbutamol in different samples. These techniques need costly equipment, competent personnel and require complex sample pretreatment procedure.

Electrochemical methods as an alternative to the above-mentioned methods for the determination of SBS and other biologically important molecules have not been studied sufficiently [23-25]. Simple set up, 
high sensitivity and do not require intensive sample preparation step as an alternative method. Determination of salbutamol in biological fluids by electrochemical methods is limited in the literature [26-29]. Amare et al. Determined SBS using the DPV method with poly 4-amino-3-hydroxynaphthalene sulfonic acid (AHNSA) / GCE [26]. Goyal et al. showed that SBS determination can be made by using SWV method with nano gold particles modified indium tin oxide (NGITO) electrode [27]. In another study by Goyal et al., determination was made with C60-modified glassy carbon electrode using SWV method [28]. Li et al. Showed that SBS determination can be made using the MIP method with Ag / N-doped reduced graphene oxide and showed the importance of SBS determination [29]. In this study, poly(benzofuran-2-boronic acid film modified $\mathrm{Pt}$ electrode was used for SBS determination. The reason for choosing this film structure is that it provides strong $\mathrm{H}$-bonding with the $-\mathrm{N}-\mathrm{H}$ and $-\mathrm{OH}$ groups on the SBS surface, allowing the SBS to be cumulated on the electrode surface and provide electrode affinity. With this poly(benzofuran-2-boronic acid film coated on the electrode surface, the electrode surface area and the electrode efficiency increased.

The aim of the study is to develop a new type of electrode that can be prepared effectively and easily in addition to the existing studies in the literature. Both DPV and SWV methods were used together in the study. EIS and Nyquist plots of the bare PtE and the BF2BA/ PtE were monitored. A new electrochemical sensor has been developed for the determination of SBS using the CV method for electropolymerization on the electrode surface, the DPV method for optimizing the polymer and the SWV methods for the determination of salbutamol. The recovery study of the developed sensor was carried out by real sample application on the synthetic urine sample.

As a result, it has been shown that the developed electrochemical method has a very good recovery (91.47 to $110.43 \%)$ with selectivity, stability, good reproducibility for SBS compared to other methods, making it a suitable method for the rapid determination of SBS in pharmaceutical samples.

\section{Materials and Methods}

\subsection{Apparatus and reagents}

All voltammetric analyzes were performed with the Ivium Vertex One brand potentiostat. The potentiostat device is controlled by Ivium Soft ${ }^{\mathrm{TM}}$ software, which is used for both data collection and data analysis and includes different electrochemical techniques. The analyses were performed by DPV, CV and SWV techniques. The bare and $\mathrm{BF} 2 \mathrm{BA} / \mathrm{PtE}$ were also characterized by EIS. Electroanalytical measurements were made in an electrochemical cell (BASi C3 Cell Stand) with a three-electrode system. In the threeelectrode system consisting of platinum electrode (BASi $\left.{ }^{\circledR}-M F-2113\right)$ as working electrode, platinum wire electrode (BASi $\left.{ }^{\circledR}-\mathrm{MW}-1032\right)$ as auxiliary electrode and $\mathrm{Ag} / \mathrm{AgCl}$ (BASi ${ }^{\circledR}-\mathrm{MF} 2052$ ) reference electrode as comparison electrode were used. Before each measurement in the voltammetric cell, nitrogen gas was passed for about 5 minutes to remove oxygen from the solution inside the cell.

3-Furan boronic acid (3FBA), benzofuran-2carboxylic acid (BF2CA), aniline-2-sulfonic acid (An2SA) and benzofuran-2-boronic acid (BF2BA) and citric acid were obtained from Sigma-Aldrich Chemical Company. Potassium ferricyanide $\left(\mathrm{K}_{3}\left[\mathrm{Fe}(\mathrm{CN})_{6}\right]\right)$, potassium dihydrogen phosphate $\left(\mathrm{KH}_{2} \mathrm{PO}_{4}\right)$, sodium monohydrogen phosphate $\left(\mathrm{Na}_{2} \mathrm{HPO}_{4}\right)$, potassium chloride $(\mathrm{KCl})$ were also purchased from Sigma-Aldrich. Sodium acetate $\left(\mathrm{CH}_{3} \mathrm{COONa}\right)$, acetic acid $\left(\mathrm{CH}_{3} \mathrm{COOH}\right)$ were purchased from Across Organics Company. Acetonitrile (AcN), Sodium hydroxide, sodium perchlorate $\left(\mathrm{NaClO}_{4}\right)$, nitric acid $\left(\mathrm{HNO}_{3}\right)$ were supplied from Merck (Darmstadt, Germany). "Ronkotol" is a liquid drug. It was purchased from the pharmacy and, was used as a source of SBS.

\subsection{Construction of the modified sensor (BF2BA/PtE)}

Firstly, monomer solutions were prepared 3-furan boronic acid (3FBA), benzofuran-2-carboxylic acid (BF2CA), aniline-2-sulfonic acid (An2SA) and benzofuran-2-boronic acid (BF2BA) in Water:AcN (1:1) mixture containing $0.1 \mathrm{M} \mathrm{NaClO}_{4}$. Platinum electrode surface was modified with each of the mentioned monomers by electrochemical method and SBS voltammetric responses of these electrodes were obtained. The best answer for SBS was obtained on the surface of modified PtE, which was produced by BF2BA ( $4 \mathrm{mM}$, 4 cycle, $50 \mathrm{mV} / \mathrm{s}$ ).

\subsection{Electrochemical procedures}

Electrochemical analyzes were performed using three different techniques such as CV, DPV and SWV techniques. CV and EIS techniques were also used to obtain information on the surface properties of the bare $\mathrm{PtE}$ and BF2BA / PtE. For CV analysis, scanning speed $50 \mathrm{mV} \mathrm{s}^{-1}$ and equilibrium time $2 \mathrm{~s}$ were used as measurement parameters in the potential range of -0.6 - 1.2 V. DPV analysis was performed after two seconds of equilibration time in the potential range 0.0 to $1.2 \mathrm{~V}$. For DPV analysis were applied as pulse amplitude 10 
$\mathrm{mV}$ and pulse time $10 \mathrm{~ms}$. As in the DPV analysis, SWV analysis was performed after two seconds of equilibration time in the potential range 0.0 to $1.2 \mathrm{~V}$. For SWV analysis was applied under optimum conditions (pulse amplitude; $20 \mathrm{mV}$, frequency; 80 $\mathrm{Hz}$ ). The standard SBS solution was prepared by citrate-phosphate buffer. Then, before making electrochemical measurements, the prepared SBS was taken from the standard solution and diluted with electrolyte solutions. The calibration curve was obtained by plotting the voltammetry oxidation peak current values on the BF2BA / PtE against increasing SBS concentrations. The limit of detection (LOD) and limit of quantification (LOQ) were calculated according to "3 $\mathrm{S} / \mathrm{m}$ " and " $10 \mathrm{~S} / \mathrm{m}$ ", respectively [30,31]. "S" in these equations is the standard deviation of the oxidation peak currents, "m" is the slope of the calibration curve. In order to test the applicability of the prepared BF2BA/PtE, electroanalytical detection study and recovery studies were performed in synthetic urine samples.

\section{Results and Discussion}

\subsection{Calculation of effective surface area}

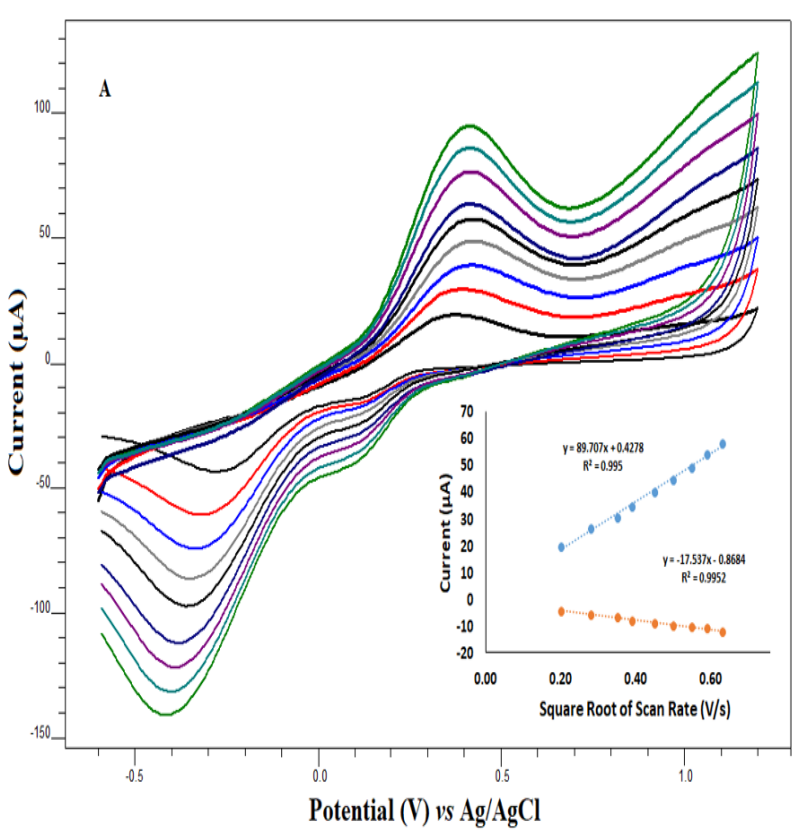

$\mathrm{CV}$ technique was used to calculate the electroactive surface areas of the electrodes. CV measurements taken with increasing scan rates were used to calculate the electroactive surface areas of the bare PtE and BF2BA/PtE. These CV results were shown in Figure 1. For calculate of the electroactive surface areas was used Randles Sevcik equation. According to Randles Sevcik equation, the square root $\left(\mathrm{v}^{1 / 2}\right)$ of increasing scanning rates against current $\left(I_{P}\right)$ values was plotted. The effective surface area of the electrode was calculated from the slope values of this curve. The peak current of a reversible electrode reaction at $25{ }^{\circ} \mathrm{C}$ is indicated by the following Randles Sevcik equation (Eq. 1).

$I_{P}=2.69 \times 10^{5} n^{3 / 2} A D^{1 / 2} v^{1 / 2} C[1]$

In the Randles Sevcik equation, Ip indicates oxidation peak current (Ampere), $\mathrm{n}$ is the number of electrons transferred, A is the surface area of the electrode $\left(\mathrm{cm}^{2}\right)$, D is the diffusion coefficient $\left(\mathrm{cm}^{2} \mathrm{~s}^{-1}\right), v$ is the scanning rate $\left(\mathrm{V} \mathrm{s}^{-1}\right)$ and $\left.\mathrm{C}(\mathrm{mol} \mathrm{cm})^{-3}\right)$ is the concentration of ferricyanide in potassium chloride electrolyte as redox probe. $\mathrm{D}$ is $6.67 \times 10^{-6} \mathrm{~cm}^{2} \mathrm{~s}^{-1}$ at constant pressure and temperature, $\mathrm{n}$ is 1 , and $\mathrm{C}$ is 6 $\mathrm{mM}$ for oxidation and reduction of potassium ferricyanide $[32,33]$.



Figure 1. The CVs of $6.0 \mathrm{mM}$ ferricyanide in $0.1 \mathrm{M} \mathrm{KNO}_{3}$ of bare PtE (A) and BF2BA modified electrode (B) at different scan rates $\left(40,80,120,160,200,250,300,350\right.$ and $\left.400 \mathrm{mV} \cdot \mathrm{s}^{-1}\right)$ (inset:peak current-square root of scan rate graphs of the bare and the modified electrode) 
As seen in the voltammograms from Figure $1 \mathrm{~A}$ and Figure $1 \mathrm{~B}$, increases in the oxidation peak are due to electrochemical stimulation. The shift of the reduction peak potential to negative and the oxidation peak potential to positive can be explained by the increase in the electron transfer rate as a result of the increase in the effective surface area of the electrode. According to the calculated results, the surface area for the bare PtE was found to be $0.0215 \mathrm{~cm}^{2}$ and the surface area after electrochemical stimulation of the prepared $\mathrm{BF} 2 \mathrm{BA} / \mathrm{PtE}$ was found to be $0.0076 \mathrm{~cm}^{2}$.

The electrochemical impedance spectroscopy (EIS) was employed for investigate the modification effect of the BF2BA/PtE. Impedance spectra were fitted to equivalent circuits (Figure 2) using ivium software. In the Nyquist curves, the increase in the diameter of the semicircle recorded at high frequencies indicates that the electron transfer speed on the electrode surface is slow, and the decrease in the diameter indicates that the electron transfer speed on the surface is high. Nyquist plots of the modified electrode represent a larger semicircle in the high frequency region than that observed for the bare electrode. From this change can be concluded that the surface resistance is greater and consequently the conductivity is lower. This change also confirms the film structure on the modified electrode surface.

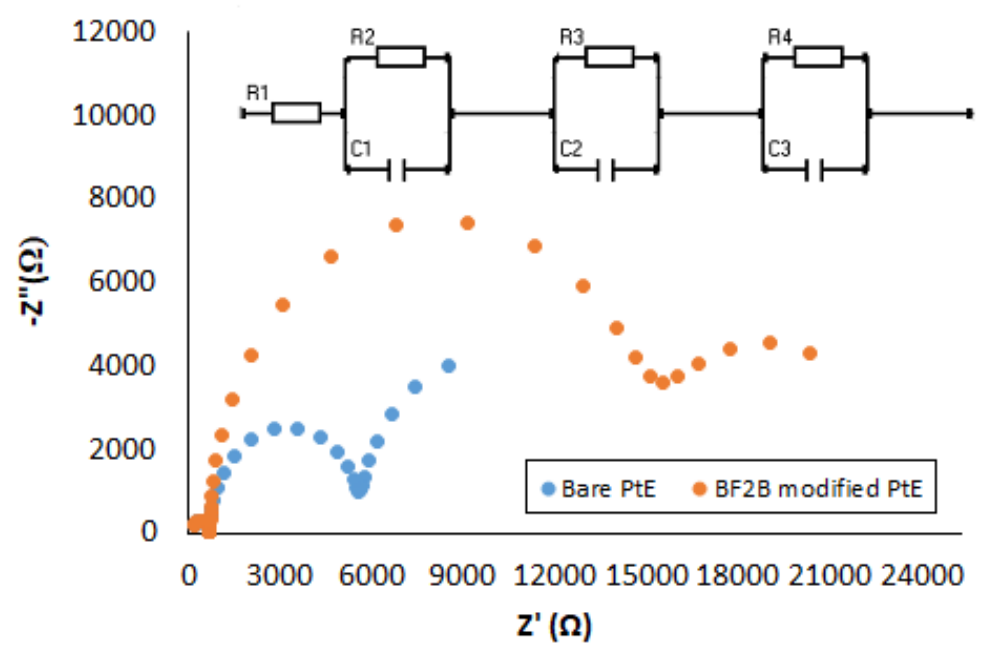

Figure 2. Impedance spectra of bare $\mathrm{PtE}$ and BF2BA/PtE.

\subsection{The effect of monomer type, concentration, film thickness and scan rate on the SBS response}

In order to examine the electrochemical behavior of SBS, firstly, it is necessary to determine of the monomer type to be used for optimum film structure was carried out by using different monomer structures. For this purpose; 3FBA, BF2CA, An2SA and BF2BA were electropolymerized on the PtE and the resulting electrodes were used for SBS determination with DPV technique. According to Figure 3, the prepare electrode with using BF2BA, was given high peak current for
$1.15 \mathrm{mM}$ SBS. Thus, BF2B/PtE was chosed the optimum electrode for SBS deduction.

The voltammograms obtained in the determination of SBS by DPV method are given in Figure 3(A). The highest peak current corresponds to PtE modified with BF2BA. The effect of BF2BA concentration $(2 ; 3 ; 4 ; 6$ and $8 \mathrm{mM}$ ) in electrode modification on SBS oxidation peak current was investigated and the optimum monomer concentration was found to be $4 \mathrm{mM}$ (Figure $3(\mathrm{~B}))$. 

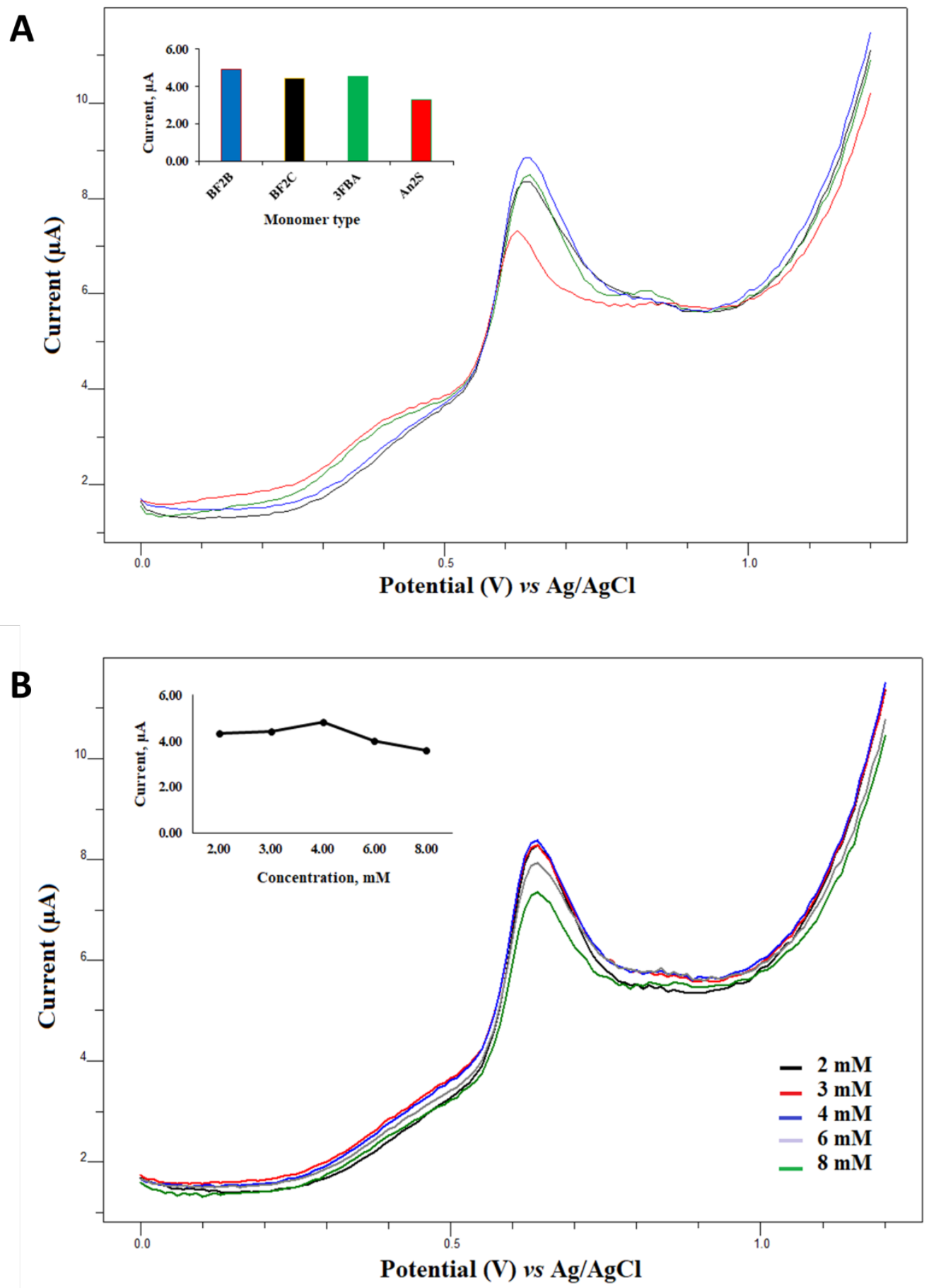

Figure 3. A; Effect of monomer type on DPV responses for $1.15 \mathrm{mM}$ SBS. B; Effect of BF2BA concentration on DPV responses for $1.15 \mathrm{mM} \mathrm{SBS}$. 

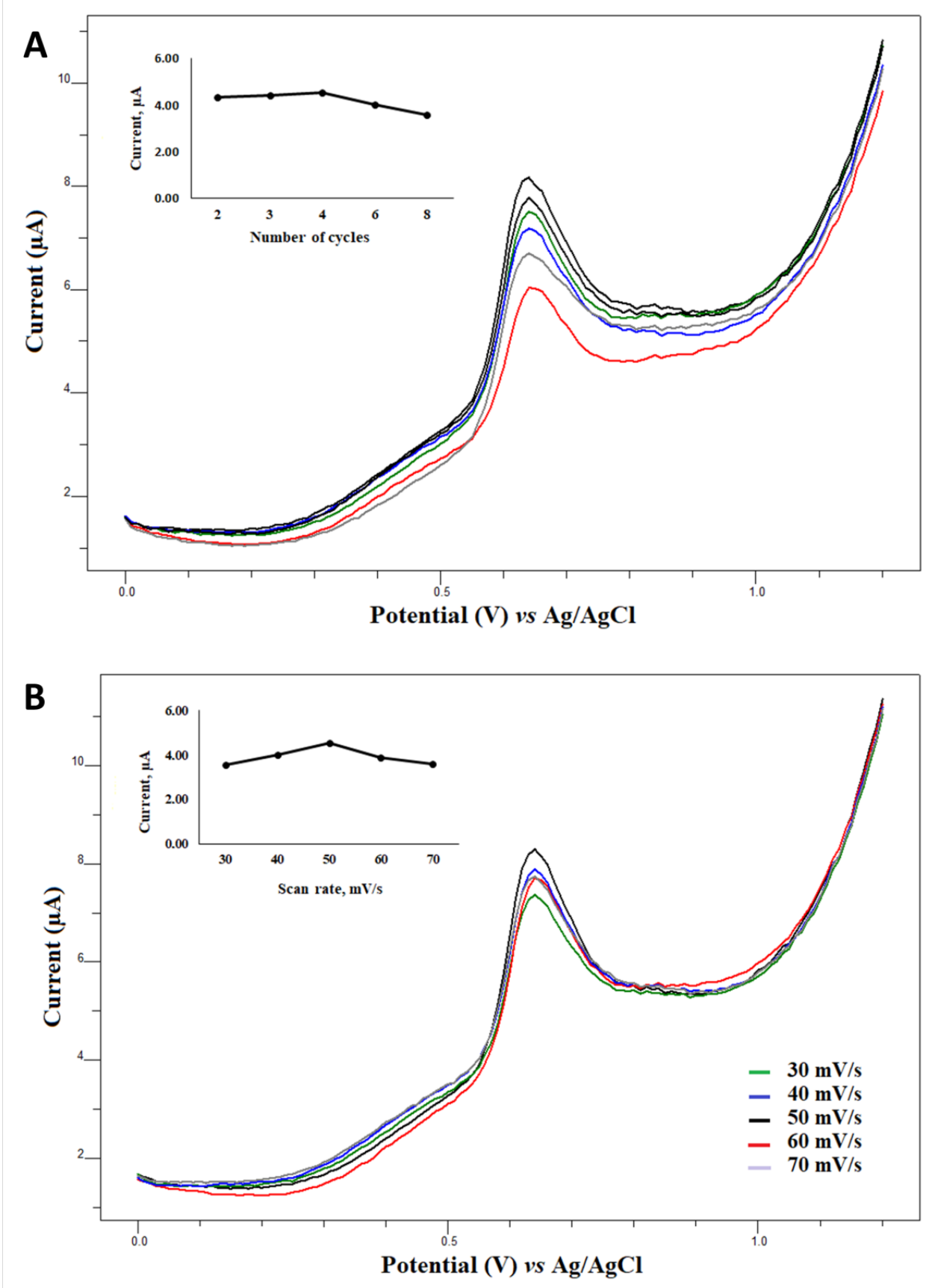

Figure 4. A; Effect of coating thickness on DPV responses for $1.15 \mathrm{mM}$ SBS. B; Effect of scan rate on DPV responses for $1.15 \mathrm{mM}$ SBS.

In this study, the thick of the polymer film was determined by studying cycle number with CV method during electropolymerization process. As shown in Figure 4(A), film thickness of 4 cycles in polymerization cycles increased the current response of SBS. As the number of cycles increased further, thicker films were formed and SBS responses decreased. From these results, it was understood that the optimum film thickness was obtained with 4 cycles, and in subsequent studies, the film thickness was used as 4 cycles. The effect of scan rate during the electropolymerization process was investigated in the range of $30-70 \mathrm{mV} / \mathrm{s}$. As can be seen in Figure 4(B), it is clear that the DPV response of the electrode modified with a scanning speed of $50 \mathrm{mV} / \mathrm{s}$ was the best.

\subsection{Influence of electrolyte type, and pH on SBS peak Current}

After selecting the monomer type, the best electrolyte solution for the analyte and the $\mathrm{pH}$ value of this electrolyte solution were determined. To determine the optimum electrolyte type for the determination of SBS, citrate buffer $(\mathrm{CB})$, acetate buffer $(\mathrm{AB})$, phosphate 
buffer (PB), Britton Robinson buffer (BRB) and citrate- phosphate buffer (C-PB) were used. The results obtained for DPV technique on modified electrode surface at different electrolyte for SBS are shown in Figure 5(A). In accordance with results, maximum and best peak currents for SBS were obtained in $0.15 \mathrm{M} \mathrm{C}$ $\mathrm{PB}$ solutions. The effect of $\mathrm{pH}$ value of the C-PB on the SBS response of the BF2BA/PtE was investigated with using 6.0, 6.5, 7.0, 7.5 and $8.0 \mathrm{pH}$ values $\mathrm{C}-\mathrm{PB}$ solutions by DPV technique. The results obtained from DPV technique on modified electrode surface at different $\mathrm{pH}$ values for SBS are given in Figure 5(B). In accordance with results, maximum and best peak currents for SBS were obtained in $0.15 \mathrm{M} \mathrm{C}-\mathrm{PB}$ at $\mathrm{pH}$ 7.5.
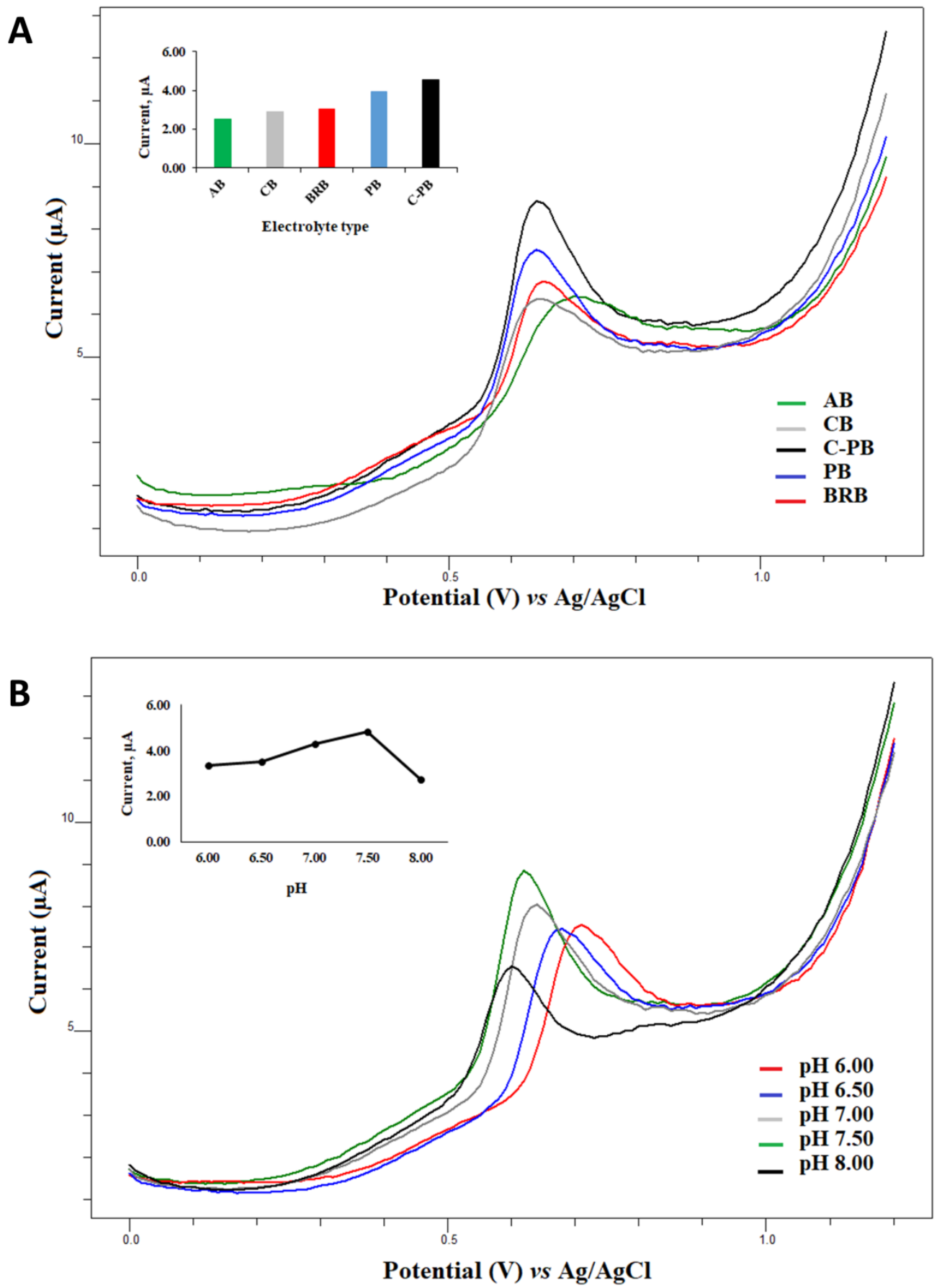

Figure 5. A;Effect of electrolyte type on DPV responses of prepared BF2BA/PtE for $1.15 \mathrm{mM} \mathrm{SBS}$. B; Effect of pH value on DPV responses of prepared BF2BA/PtE for $1.15 \mathrm{mM} \mathrm{SBS}$. 


\subsection{Optimizations of the SWV technique (Accumulation potential and pccumulation time)}

The SWV technique was more sensitive and is a more suitable technique for analyzing low concentration analytes than the DPV technique. Therefore, SWV technique was used in quantitative studies of SBS. The effect of the accumulation potential to the SBS peak current for $10 \mathrm{~s}$ and $300 \mathrm{rpm}$ in $0.15 \mathrm{M} \mathrm{pH} 7.50$ citratephosphate buffer was investigated by SWV in the range 0.25 to $0.45 \mathrm{~V}$ (Figure 6(A)). The results showed that optimum accumulation potential increased up to $0.35 \mathrm{~V}$ and then decreased. Therefore, it was decided to operate at a potential of $0.35 \mathrm{~V}$ in subsequent studies.
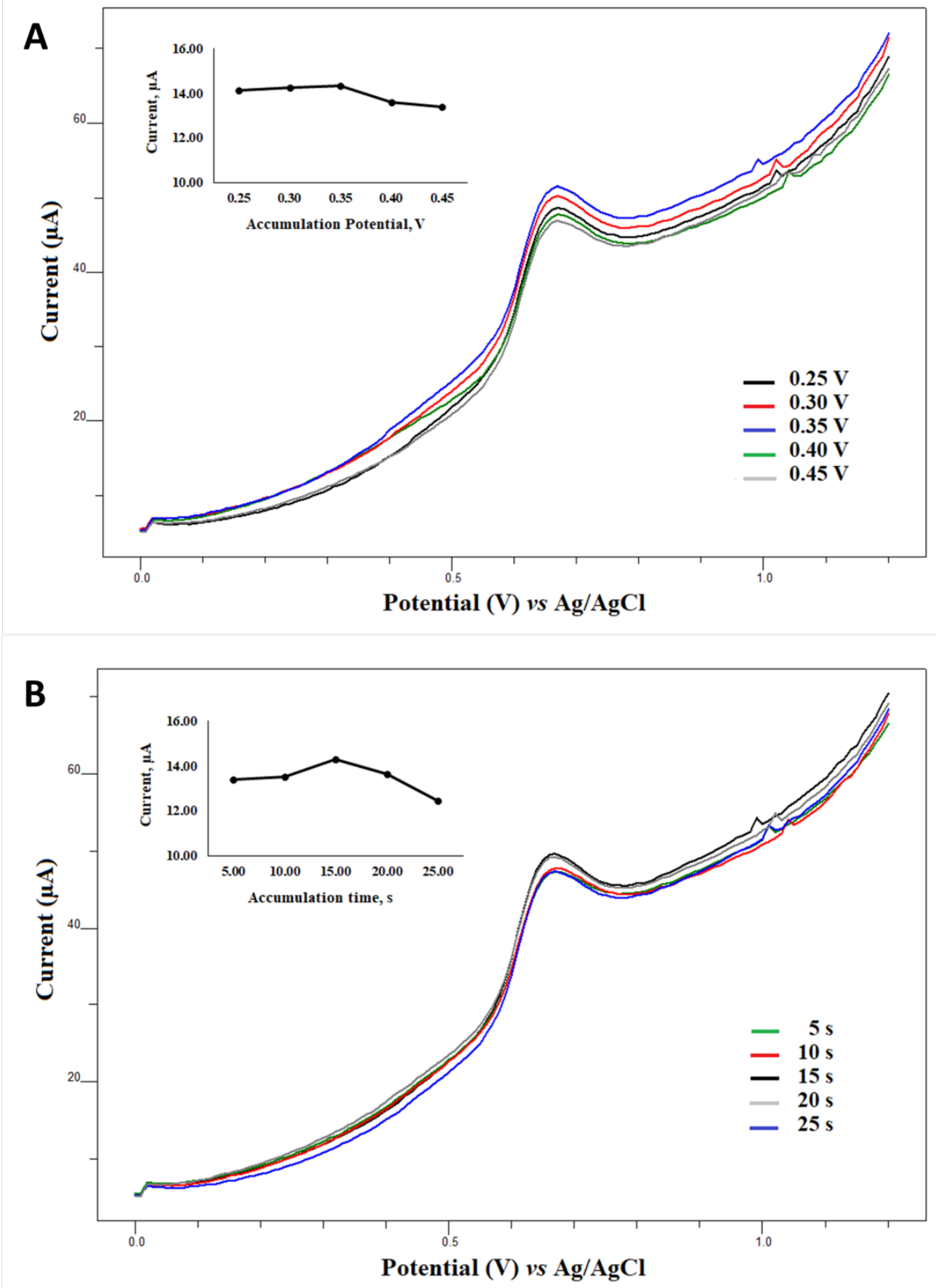

Figure 6. A; Effect of accumulation potential on 1.15 mM SBS SWV peak current in 0.15 M C-PB, pH 7.50. B; Effect of accumulation time on 1.15 mM SBS SWV peak current in 0.15 M C-PB, pH 7.50. 
In order to determine the effect of the accumulation time on the SBS voltammetric response, it was studied in the range of 5-25 $\mathrm{s}$ and the voltammograms obtained were examined. According to these results, the optimum accumulation time was $15 \mathrm{~s}$ (Figure 6(B)).

\subsection{Analytical parameters of the prepared modified electrode}

SWV measurements were carried out with BF2BA/PtE at increasing SBS concentrations under optimal experimental conditions. SWV responses obtained at increasing SBS concentrations are given in Figure 7. Peak currents increased linearly with increasing SBS concentration. According to SWV measurement results from Figure 3 to Figure 6, the electrochemical performance and SBS selectivity of the modified electrode were determined. With the developed sensor, it has ensured the sensitive and selective determination of SBS in a wide linear range of 50-2000 $\mu \mathrm{M}$ and the obtained calibration curve given in Figure 7 (inset). With the calibration curve obtained, LOD value for the modified electrode was determined. The LOD value of the modified electrode was calculated with the equation $\mathrm{LOD}=3 \mathrm{~S} / \mathrm{m}$ ( $\mathrm{S}$ standard deviation; $\mathrm{m}$ is the slope of the calibration curve) and was determined as $49.14 \mu \mathrm{M}$. The LOQ value of the modified electrode was calculated with the equation LOQ $=10 \mathrm{~S} / \mathrm{m}$ and was determined as $163.80 \mu \mathrm{M}$.

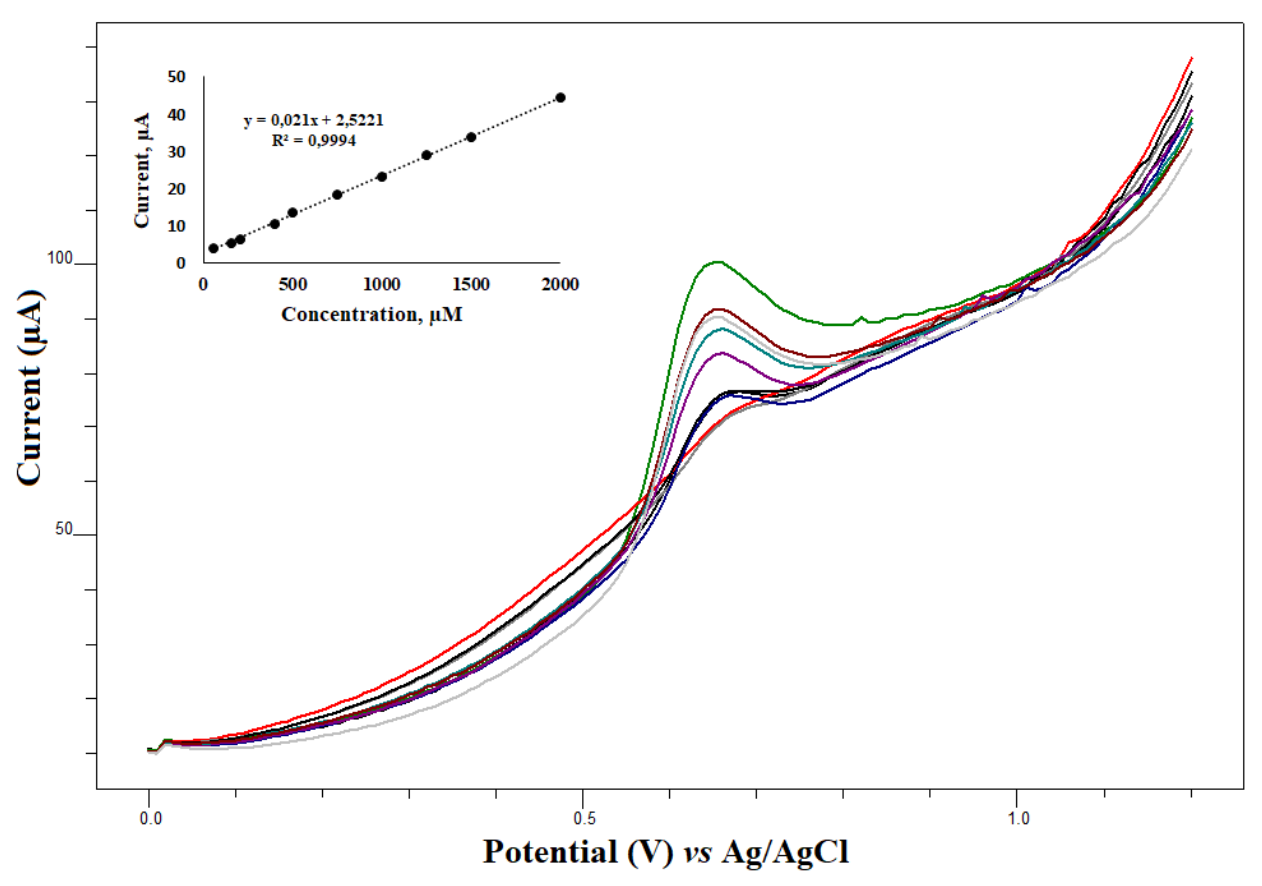

Figure 7. SWV responses of BF2BA modified electrode at 50, 150, 200, 400, 500, 750, 1000, 1250, 1500 and $2000 \mu \mathrm{M}$ SBS concentrations. Calibration curve for increasing SBS concentrations (inset).

\subsection{Reproducibility results of the prepared modified electrode}

To test the reproducibility of the prepared electrodes, SWV responses were received of $500 \mu \mathrm{M}$ SBS solutions in $0.15 \mathrm{M} \mathrm{C}-\mathrm{PB}(\mathrm{pH} 7.50)$ on BF2BA/PtE. The voltammograms obtained for reproducibility results of modified electrode are given in Figure 8. The reproducibility of the voltammetric responses obtained with ten measurements using the modified electrode indicates that the stability of the present method is very good. According to the voltammograms obtained, SBS peak currents are given as bar graphs in Figure 8(inset graph). The standard deviation and the $\%$ relative standard deviation (\% RSD) of modified electrode calculated 0.14 and 1.11 respectively, from the bar graph in Figure 8. As a result, the reproducible, highly stable and extremely sensitive $(98.89 \%)$ of prepared sensor and SBS determination method proved. 


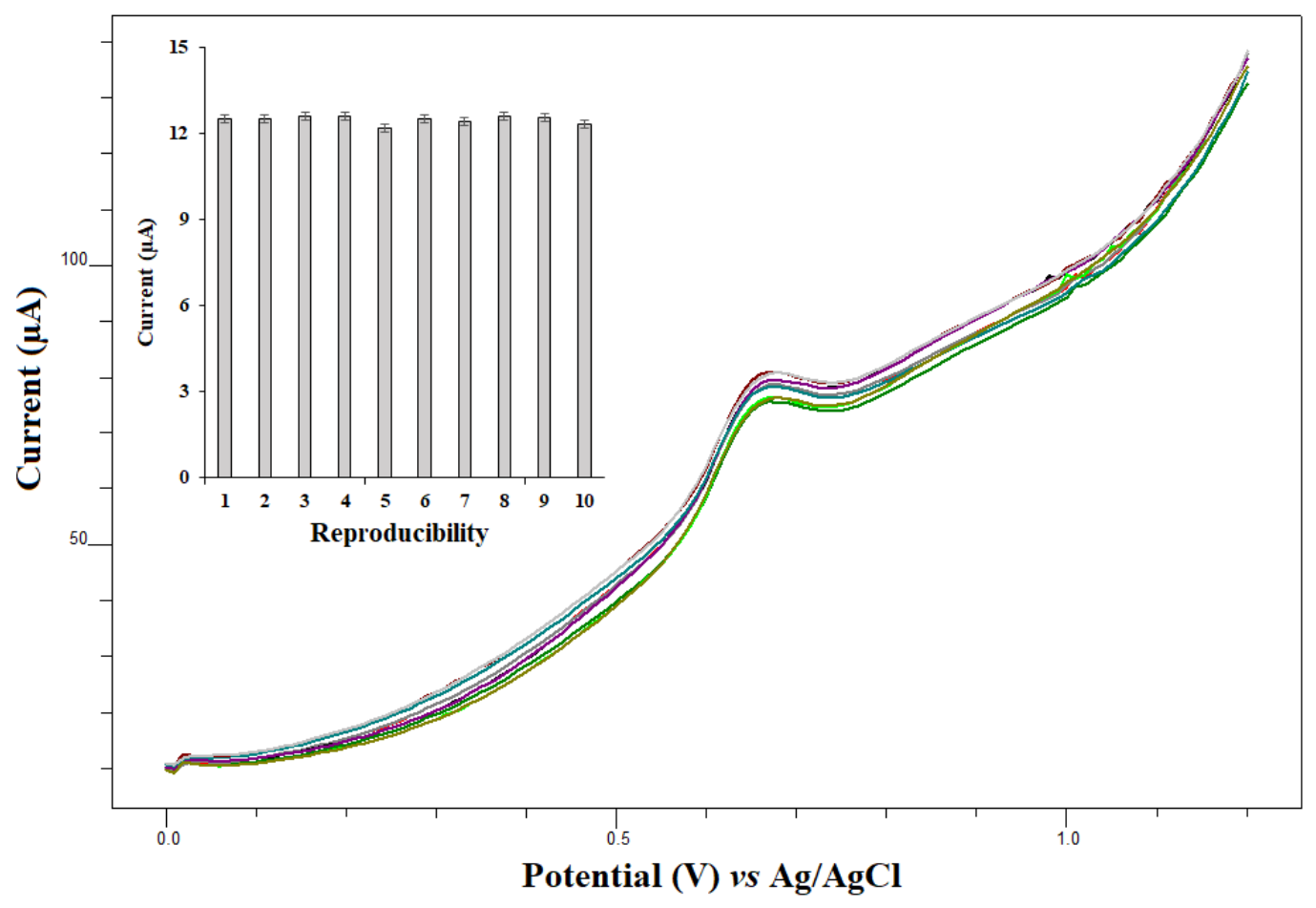

Figure 8. The reproducibility of BF2BA/PtE in C-PB for $500 \mu \mathrm{M}$ SBS (pH 7.50) $(\mathrm{n}=10)$. Inset graph; reproducibility bar graph of BF2BA/PtE.

\subsection{Interference effect on the SBS determination}

In order to evaluate the selectivity of the modified electrode, some biological molecules (dopamine (DA), uric acid (UA) and glucose (GC)) were tested under optimized conditions. The interferent study was carried out in the presence of $50 \mu \mathrm{M}$ concentration of various non-target agents. No interference in the voltammograms was observed as shown in Figure 9, which confirmed excellent specificity of the electrode. Therefore, the designed modified electrode has good selectivity for the determination of low levels of analytes.

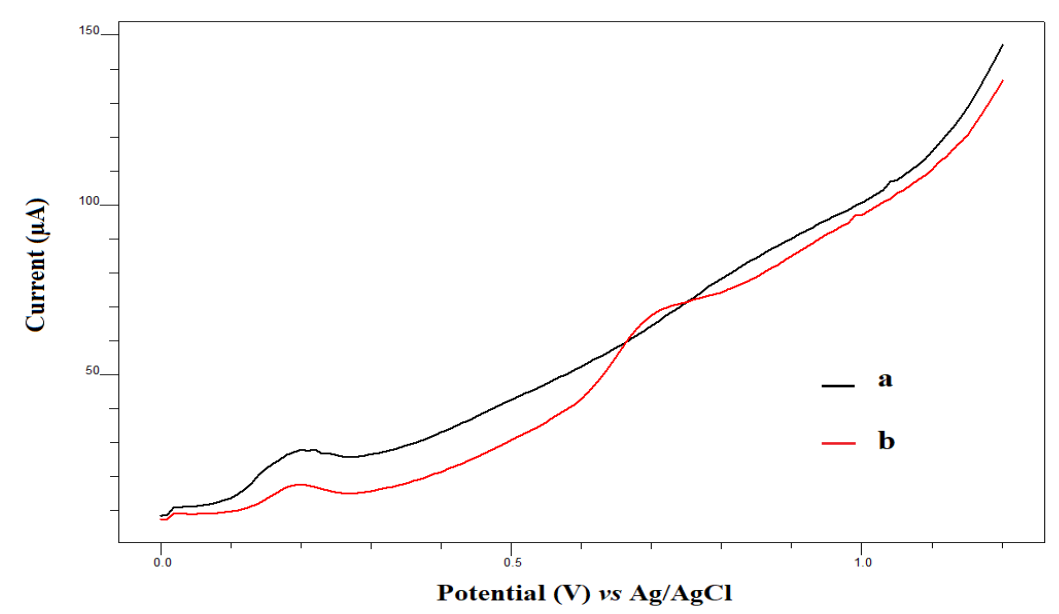

Figure 9. SWV Curves of BF2BA/PtE in C-PB a) in the presence of $50 \mu \mathrm{M} \mathrm{DA}, \mathrm{UA}$ and GC, b) in the presence of $50 \mu \mathrm{M}$ UA, DA and GC with $500 \mu \mathrm{M}$ SBS.

\subsection{Real sample analysis}

In order to test the applicability of the produced BF2BA / PtE, the SWV technique was used to determine the amount of SBS in synthetic urine samples. 
Table 1. Analysis of synthetic urine sample added to SBS standard solution using SWV technique.

\begin{tabular}{lccccc}
\hline Sample & $\begin{array}{c}\text { Original found in } \\
\text { sample }\left(\mu \mathrm{molL}^{-1}\right)\end{array}$ & $\begin{array}{c}\text { Standard added } \\
\left(\mu \mathrm{molL}^{-1}\right)\end{array}$ & $\begin{array}{c}\text { Total Found } \\
(\mu \mathrm{molL})^{\mathrm{a}}\end{array}$ & $\begin{array}{c}\mathrm{RSD}^{\mathrm{b}} \\
(\%)\end{array}$ & $\begin{array}{c}\mathrm{R} \\
(\%)\end{array}$ \\
\hline $\begin{array}{l}\text { Synthetic } \\
\text { urine }\end{array}$ & Not detected & 50.00 & $50.84 \pm 0.010$ & 0.386 & 101.68 \\
$\begin{array}{l}\text { Synthetic } \\
\text { urine }\end{array}$ & Not detected & 150.00 & $153.32 \pm 0.003$ & 0.064 & 102.22 \\
$\begin{array}{l}\text { Synthetic } \\
\text { urine }\end{array}$ & Not detected & 200.00 & $220.86 \pm 0.012$ & 0.171 & 110.43 \\
\hline
\end{tabular}

a) Average of three measurements. b) RSD is three replicate of found concentration.

High peak current values, which are oxidized at the the table, detection of SBS contentin the range 101.68 same potentials, are acquired with the SWV technique. to $110.43 \%$ of the labeled value showed good Three consecutive concentrations were added to the agreement. According to the results obtained, it is synthetic urine sample to determine the SBS in the consistent with the amount of SBS of the proposed flacon samples with the electrodes obtained with the method with recovery value for determining the BF2BA modification of Pt. The recovery results amount of SBS in flacon samples.

obtained were given in Table 1. As can be seen from

Table 2. The comparison of SBS detection methods with the literature

\begin{tabular}{lllll}
\hline Methods & $\begin{array}{l}\text { Electrode/ Modifier } \\
\text { sensors }\end{array}$ & Linear range, M & LOD, M & Ref \\
\hline DPV & GCE/ AHNSA & $0.2 \times 10^{-6} \sim 8.0 \times 10^{-6}$ & $6.8 \times 10^{-8}$ & {$[26]$} \\
SWV & NGITO & $2.09 \times 10^{-11} \sim 9.5 \times 10^{-12}$ & $3.13 \times 10^{-11}$ & {$[27]$} \\
MIP & Ag-N-RGO & $0.03 \times 10^{-6} \sim 20.0 \times 10^{-6}$ & $7.0 \times 10^{-9}$ & {$[29]$} \\
& GCE/ NiFe $2 \mathrm{O}_{4}$ & $2.0 \times 10^{-6} \sim 60.0 \times 10^{-6}$ & $1.0 \times 10^{-6}$ & {$[34]$} \\
SWV & GCE/MWNT & $8.0 \times 10^{-7} \sim 1.0 \times 10^{-5}$ & $2.0 \times 10^{-7}$ & {$[35]$} \\
SWV & PtE/ BF2BA & $50.0 \times 10^{-6} \sim 2000 \times 10^{-6}$ & $49.14 \times 10^{-6}$ & This study \\
\hline
\end{tabular}

GCE/ AHNSA : glassy carbon electrode/ 4-amino-3- hydroxynaphthalene sulfonic acid

NGITO : nanogold modified indium tin oxide electrode

MIP : molecularly imprinted polymer

$\mathrm{GCE} / \mathrm{NiFe}_{2} \mathrm{O}_{4} \quad$ : glassy carbon electrode $/ \mathrm{NiFe}_{2} \mathrm{O}_{4}$ nanoparticles

GCE/MWNT : glassy carbon electrode/ multicarbon nanotubes

PtE/ BF2BA : platinum electrode / benzofuran-2-boronic acid

The comparison of SBS detection methods with the literature was given in Table 2. According to Table 2, prepare electrode has short response time, easy preparation advantage and high reproducibility. Thus, prepared $\mathrm{BF} 2 \mathrm{BA} / \mathrm{PtE}$ has the potential to be used in biomedical applications and in the medical field.

\section{Conclusions}

In this study, firstly, the modification of $\mathrm{Pt}$ with BF2BA electrode was successfully produced by electropolymerization. Then, electroanalytical SBS responses of prepared BF2BA/PtE were investigated in C-PB ( $\mathrm{pH}$ 7.50) solution by Cyclic Voltammetry, 
Differential Pulse Voltammetry and Square Wave Voltammetry techniques. The electrochemical performance of the BF2BA/PtE was also confirmed by $\mathrm{CV}$ and EIS experiments. The low LOD and LOQ values were obtained with the prepared modified electrode for the determination of SBS. The developed method was applied with $91.47 \%-110.43 \%$ recovery of SBS in the flacon sample. The applications of the BF2BA/PtE have proven to show excellent reproducibility and stability. As a result, synthetic urine sample applications have confirmed that the method has been applied successfully. Thus, it has been proved that SBS in real samples can easily detect with the developed novel BF2BA/PtE and this $\mathrm{BF} 2 \mathrm{BA} / \mathrm{PtE}$ has the potential to be used in biomedical applications and in the medical field.

\section{Conflicts of interest}

The author simply declares there is no conflict of interest.

\section{References}

[1] Barisione G., Baroffio M., Crimi E., Brusasco V., Beta-Adrenergic Agonists, Pharmaceuticals, 3 (2010) 1016-1044.

[2] Shihab A. I., Al-Sabha N. T., Application of Cloud Point Method for Spectrophotometric Determination of Salbutamol Sulphate and Methyldopa, Pak. J. Anal. Environ. Chem., 21 (1) (2020) 10-18.

[3] Balanag V.M., Yunus F., Yang P.C., Jorup C., Efficacy and safety of budesonide formoterol compared with salbutamol in the treatment of acute asthma, Pulm. Pharmacol. Ther., 19 (2) (2006) 139-147.

[4] El-Enany N., Belal F., Rizk M., A simple kinetic spectrophotometric method for the determination of salbutamol in dosage forms, Chem. Anal. (Warsaw, Poland) 49 (4) (2004) 587-599.

[5] Habib I.H.I., Hassouna M.E.M., Zaki G.A., Simultaneous Spectrophotometric Determination of Salbutamol and Bromhexine in Tablets, $I l$ Farmaco, 60 (3) (2005) 249-254.

[6] Kalyani L., Chava V.N. Rao, Simultaneous spectrophotometric estimation of Salbutamol, Theophylline and Ambroxol three component tablet formulation using simultaneous equation methods, Karbala International Journal of Modern Science, 4(1) (2018) 171-179.

[7] Ayad M. M., Abdellatef H. E., Hosny M. M., Abdel-Sattar Kabil N., Spectrophotometric
Determination of Etilefrine $\mathrm{HCl}$, Salbutamol Sulphate and Tiemonium Methyl Sulphate Using Surface Plasmon Resonance Band of Gold Nanoparticles, Nano Biomed. Eng., 10(1) (2018) 16-24.

[8] R'afat M. N., Mahmoud M. I., Mozer H. AL-K., Akila A. S., Alaa A. S., Raluca van S. I. S., Hassan Y. A.-E., Development and validation of kinetic and atomic absorption spectrophotometric methods for the determination of salbutamol sulfate, RSC Advances, 5(70) (2015) 5716457170.

[9] Gabiola C., Garcia-Calonge M.A., Portillo M.P., Martinez J.A., del Barrio A.S., Validation of a method for the determination of salbutamol in animal urine by gas chromatography-mass spectrometry and its application to treated lamb samples, J. Microcol., 8(5) (1996) 361-364.

[10] Liu H., Gan N., Chen Y., Ding Q., Huang J., Lin S., Cao Y., Li T., Novel method for the rapid and specific extraction of multiple $\beta$-agonist residues in food by tailor-made monolith-MIPs extraction disks and detection by gas chromatography with mass spectrometry, J Sep Sci., 39(18) (2016) 3578-3585

[11] Sutariya V.B., Mashru R.C., Sankalia M.G., Sankalia J.M., Liquid chromatographic determination and pharmacokinetics study of salbutamol sulphate in rabbit plasma, ArsPharm., 47(2) (2006) 185-197.

[12] Kulikovskii AV, Lisitsyn AB, Gorlov IF, Slozhenkina MI, Savchuk SA. Determination of growth hormones ( $\beta$-agonists) in muscle tissue by HPLC with mass spectrometric detection, $J$ Anal Chem., 71(10) (2016) 1052-1056.

[13] Chang K.-C., Chang Y.-T., Tsai C.-E., Determination of ractopamine and salbutamol in pig hair by liquid chromatography tandem mass spectrometry, Journal of Food and Drug Analysis, 26(2) (2018) 725-730.

[14] Zhang L.Y., Chang B.Y., Dong T., He P.L., Yang W.J., Wang Z.Y., Simultaneous Determination of Salbutamol, Ractopamine, and Clenbuterol in Animal Feeds by SPE and LC-MS, Journal of Chromatographic Science, 47(4) (2009) 324-328.

[15] Chan S.H., Lee W., Asmawi M.Z., Tan S.C., Chiral liquid chromatography-mass spectrometry (LC-MS/MS) method development for the detection of salbutamol in urine samples, $J$. Chromatogr. B., 1025 (2016) 83-91. 
[16] Changguo C., Hong L., Yujing F., Determination of salbutamol sulfate in medicaments by capillary electrophoresis with contactless conductivity detection, Chin. J. Chromatogr., 29(2) (2011) 137-140.

[17] Sirichai S., Khanatharana P., Rapid analysis of clenbuterol, salbutamol, procaterol, and fenoterol in pharmaceuticals and human urine by capillary electrophoresis, Talanta, 76(5) (2008) 11941198.

[18] Nguyen T.A.H., Pham T.N.M., Doan T.T., Ta T.T., Saiz J., Nguyen T.Q.H., Hauser P.C., Mai T.D., Simple semi-automated portable capillary electrophoresis instrument with contactless conductivity detection for the determination of beta-agonists in pharmaceutical and pig-feed samples, J. Chromatogr. A., 1360 (2014) 305311.

[19] Lodén H., Pettersson C., Arvidsson T., Amini A., Quantitative determination of salbutamol in tablets by multiple-injection capillary zone electrophoresis, J. Chromatogr. A., 1207 (1-2) (2008) 181-185.

[20] Chen Q., Fan L.-Y., Zhang W., Cao C.-X., Separation and determination of abused drugs clenbuterol and salbutamol from complex extractants in swine feed by capillary zone electrophoresis with simple pretreatment, Talanta, 76(2) (2008) 282-287.

[21] Lindino C.A., Bulhões L.O.S., Determination of fenoterol and salbutamol in pharmaceutical formulations by electrogenerated Chemiluminescence, Talanta, 72(5) (2007) 17461751.

[22] Barnett N. W., Hindson B. J., Lewis S. W., Determination of Ranitidine and Salbutamol by Flow Injection Analysis with Chemiluminescence Detection, Analytica Chimica, 384(2) (1999) 151158.

[23] Demir E., İnam O., İnam R., Determination of ophthalmic drug proparacaine using multi-walled carbon nanotube paste electrode by square wave stripping voltammetry, Analytical Sciences, 34 (2018) 771-776.

[24] İnam O., Demir E., Uslu B., Voltammetric Pathways for the Analysis of Ophthalmic Drugs, Current Pharmaceutical Analysis, 16 (2020) 367391.

[25] Güngör Ö., Kılıç B., Karasürmeli T.S., Özcan İ., Köytepe S., Voltammetric determination of alpha lipoic acid using chitosan-based polyurethane membrane electrode, Measurement, 182 (2021) 109752.

[26] Amare M., Menkir G., Differential pulse voltammetric determination of salbutamol sulfate in syrup pharmaceutical formulation using poly(4-amino-3- hydroxynaphthalene sulfonic acid) modified glassy carbon electrode, Heliyon, 3(10) (2017) e00417.

[27] Goyal R.N., Oyama M., Singh S.P., Fast determination of salbutamol, abused by athletes for doping, in pharmaceuticals and human biological fluids by square wave voltammetry, $J$. Electroanal. Chem., 611(1-2) (2007) 140-148.

[28] Goyal R.N., Kaur D., Singh S.P., Pandey A.K., Effect of graphite and metallic impurities of C60 fullerene on determination of salbutamol in biological fluids, Talanta, 75(1) (2008) 63-69.

[29] Li J., Xu Z., Liu M., Deng P., Tang S., Jiang J., Feng H., Qian D., He L., Ag/N-doped reduced graphene oxide incorporated with molecularly imprinted polymer: An advanced electrochemical sensing platform for salbutamol determination, Biosensors and Bioelectronics, 90 (2017) 210216.

[30] Miller J.C., Miller J.N., Statistics for Analytical Chemistry, New York: Halsted Press, (1984).

[31] Riley M., Rosanske T.W., Development and validation of analytical methods, New York: Elsevier Science Ltd., (1996).

[32] Bard A.J., Faulkner L.R., Electrochemical Methods (2nd edition), New York: John Wiley \& Sons, Inc., (2001), 166.

[33] Huang T.-Y., Kung C.-W., Wei H.-Y., Boopathi K.M., Chu C.-W., Ho K.-C., A High Performance Electrochemical Sensor for Acetaminophen Based on a rGO-PEDOT Nanotube Composite Modified Electrode, J. Mater. Chem. A, 2 (2014) 7229-7237.

[34] Luo S.X., Wu Y.H., Gou H., Liu Y., A Novel Electrochemical Sensor for the Analysis of Salbutamol in Pork Samples by Using $\mathrm{NiFe}_{2} \mathrm{O}_{4}$ Nanoparticles Modified Glassy Carbon Electrode, Advanced Materials Research, 850851 (2014) 1279-1282.

[35] Wei Y., Zhang Q., Shao C., Li C., Zhang L., Li X., Voltammetric Determination of Salbutamol on a Glassy Carbon Electrode Coated with a Nanomaterial Thin Film, Journal of Analytical Chemistry, 65(4) (2010) 398-403 